\title{
Profile Gender: The Study of Education, Health, Labor, and Social Culture
}

\author{
Edi Widianto \\ Nonformal Education, Faculty of Education, Universitas Negeri Malang \\ Malang, Indonesia \\ Corresponding e-mail: edi.widianto.fip@um.ac.id
}

\begin{abstract}
The gap between men and women in aspects of life bring problems which hamper national development, in which the role of women was less than the male role. The purpose of this study was to: determine tersedianya data and information education by gender and level of education, aware of the available data and information in the case of health and sex, knowing the data and information economics, 4) see the data and information of social and cultural fields represented cases of early marriage. This study uses descriptive qualitative research design. Multi-case studies in this research is a social case study mainly women in Nganjuk. Collecting data using techniques: in-depth interviews, participant observation and document study. The results showed: the profile of gender education in segregation between men and women has been summarized well, the profile of gender in health in the segregation between men and women is not maximized, the profile of gender economics and employment in the segregation between men and women not maximum, the gender profile of socio-cultural field that focuses on marriage, is a determining factor of gender inequality.
\end{abstract}

Keywords: $\quad$ profile, gender, education, health, labor, social culture.

\section{INTRODUCTION}

Gender discrimination in Indonesia is still very real in many fields. Gender is a concept that is used to identify differences in men and women in terms of socio-cultural influences. Gender in this sense is an engineered form of society (social constructions), gender is not something that is natural. Gender inequalities are not natural, it means that they are not the result of biology or of the differences between female and male bodies (Steffena \& Krob, 2015). Gender discrimination has always been a debate among academics and non-academics from age to age. This problem will continue to be appointed along women really feel their rights and there is no gender bias. Perhaps we have heard or said that women are creatures into two, it means there is a difference between men and women, where women have no rights as men. This has implications for women's condescension which is regarded as being number two should not get the same rights as men, for example in education, employment or even politics and should not be voicing their rights. Although women are entering the job market in large numbers and the prevailing gender systems on the island support this integration, wages in the industry Werner discriminatory (Ramirez, et al., 2015). As in classical terms mentioned duties of women cannot be more than just in the kitchen, wells, and mattresses. The dominance of the male role in the public sector, while the limited role of women in the domestic sector is socially constructed and thus had to be reconstructed gender justice.

The gap between men and women in various aspects of life is then brought to the problems which hamper national development, in which the role of women felt 'less' than the role played by men as rulers in various aspects of life in which the role of women involved in national development at all. Gender discrimination on the labor market can take various forms, ranging from the restriction to work in a Certain area or to fill in Certain positions (professional discrimination), to wage difference (wage discrimination) for the work completed under the same conditions and with the same results (Turturean, et al., 2013).

Promoting gender equality and women's empowerment were announced by the government through the MDG's is considered very important for national development is an obligation for all citizens including women. Therefore, the role of women is also considered important to participate in national development. The role of women not only as 
in the description above because it was time position of women must be recognized and be aligned as the role played by men. Gender equality is an effort or strategy that should be taken to provide opportunities to all components in order to play an optimal role in development. Gender equality into all national development process is necessary to improve the position, role, and the quality of women. Thus, Gender Studies contribute to a more human, equitable and solidarity education (Steffena \& Krob, 2015).

One of the objectives of the Millennium Development Goals (MDGs) of the eight objectives that have been declared by the United Nations (UN) in 2000 is encouraging gender equality and women's empowerment. In order to reduce the gender gap government through policy and program development has sought to integrate the experiences, aspirations, needs and problems of women and men into the planning, implementation, monitoring and evaluation of national development programs which require genderdisaggregated data.

It must be recognized that efforts to achieve the MDGs in the region is still very heavy. This condition cannot be separated from the other major processes, namely the transition to democracy as a consequence of the reform and the implementation of regional autonomy. Lots helm of the region, policy makers, legislators, and local planners who are less aware of MDG targets and strategies. In addition to still more evidence of the lack of commitment to building the region and community, as well as carrying out the mandate of the MDGs.

Carry out development with due regard to gender equality became one of the requirements to achieve gender equitable development and bring benefits for both men and women. One of the requirements to achieve development that takes into account gender equality is the gender analysis of each development program implemented in all sectors of development. This analysis can only be carried out if the program planners and decision makers to understand about gender justice and its application in development programs and always follow the latest gender issues in the community that continues to grow.

Most of the development process in the hands of local governments. An understanding of local conditions is necessary, particularly in the development efforts of women's empowerment and child protection. With the gender profile of women are expected to describe various gender issues which have been neglected or have not worked optimally, especially in areas that are still lagging behind.

In the system of national planning, gender issues in the area also illustrates the national problem that must be followed in a comprehensive and sustained by the region. Profile analysis done at the district level will be a very valuable input in the planning of national development innovation. In addition, the data and information on the gender gap may be used to integrate gender into various development sectors, among other strategic sectors of the economy, education, social, cultural, legal, political, and health. To better manage innovation processes, it is essential to better understand human factors of innovation (Jung \& Ejermo, 2014). Availability of facts, data, and information about the gender gap, in the form of disaggregated data and the fact the gender gap in various development sectors is also needed because it can provide a clear picture of the position of men and women.

\section{METHOD}

This study used a qualitative research design. Researchers conducted the interpretation of the issues studied, because the main characteristics of the subjective qualitative-interpretive. This study followed the advice given by Bogdan \& Biklen (2007), which uses multi-case study design (multi-case studies). Application of multi-case study design starts from a single case first, and then continued in the second and third cases.

By paying attention to the existence and reality of each gender characteristics in Nganjuk, then this type of study is a multi-case study with descriptive format. Multi-case studies in this research is a social case study mainly women, which saw the sides of the gender equalityand the efforts of empowerment and protection of women, especially in cases of early marriage.

Primary data were obtained from informants related to behavior. In this study takes the case of early marriage and the data taken from the offender, parents, community leaders, and the environment. Secondary data were obtained from documents, photographs, and objects that can be used as a complement to the primary data. Collecting data using techniques: in-depth interviews, participant observation, and literature study.

Determination of informants to be studied procedures are purposively. Purposive 
procedure is one of the strategies determine informants by determining who become informants in accordance with the selected criteria that are relevant to the research problem (Bungin, 2011: 107). The criteria for informants in this study include: (a) the religious leaders and community leaders who understand gender in Nganjuk, (b) women involved in the social sectors of culture including in this case the perpetrators of early marriage along with the family and the surrounding community, and (c) the data from the sectoreducation, health and employment. The data collection is also done through documentation SKP in Nganjuk as interviews with offenders in the community. Another criterion is the person who has special knowledge, informative, and to better understand the situation that the focus of research, namely on gender and those who organized the program and is involved in gender activities.

Data analysis is the process of systematically search for and organize all interview transcripts, field notes, and other materials that have been mustered to acquire knowledge and experience about the data, and communicate what has been discovered (Bogdan \& Biklen, 2007). The activities carried out in the data analysis include: organize, sort, categorize, coding and categorizing with the aim of finding the findings (Moleong, 2007).

Analysis of the data used by: (1) find the domain-domain analysis, (2) domain analysis mapped as a single domain or multiple, (3) if a single domain, then the case study carried out by describing a domain that is based on the phenomenon of vertical, such as the development of the Unexplained the phenomenon or horizontally, like dynamics or changes in phenomena of people in the case studies, (4) if multiple domain then the case study can be done other than to explain a single phenomenon, also describes the relationships between domains that (Bungin, 2011: 237). Further analysis of the data after data collection is done with the model, namely: (1) data reduction, (2) data display, (3) drawing conclusion.

In the qualitative approach, the research instrument is the researcher himself (Lincoln \& Guba, 1985). To avoid data bias, then testing the validity of the data that aims to prove that what was observed by researchers in accordance with the conditions that exist in the real world, and in accordance with what is actually there and happening. Data validity in qualitative research to meet the criteria that the data and information collected researcher contain emic truth value is good for readers who are critical, as well as for the subject under study. Bogdan and Biklen (2007) states in the study with a qualitative approach, the researcher is the main instrument. Therefore, the validity and reliability of research instrument is not by way of test instruments,

The validity of the data is very important in qualitative research. The information has been collected by investigators and will be used as the data in this study need to be examined its credibility, so that the study's data can be accounted for and can be used as a solid foundation in making conclusions. Test the validity of the data is done by triangulation of data sources. Triangulated with the data source of data is done by comparing the observed data with the results of interviews, and compare the results of interviews with a related document (Bungin, 2011: 265). Validity of the data used in this study was to compare with the data source.

\section{RESULTS}

\subsection{Gender Profiles in Education}

Education should be a measure to determine the civilization of a society, because education is an investment in a nation's civilization. An area can be said to have a level of knowledge and skills well when a high level of education. Levels of education itself is measured from the highest education attained by a society or population in a given region. Research findings showed that the percentage of the population aged over 10 years who had completed higher education is still dominated by men ranging from elementary school until college. That is, the level of female education in Nganjuk require attention in achieving gender equality in education.

Here is the percentage of the highest education attained by the population by sex. Comparison of the number of people who have never attended school is still dominated by women that is equal to $9.44 \%$ as compared to men who only $7.08 \%$. The men were studying at the college level as much as $8.02 \%$ while women who graduated from college only amounted to $7.18 \%$. Thus, the percentage of people who do not / have not been to school and not / do not complete primary school is greater among females than males. While the percentage of people who complete college 
level education dominated by men than women.

\section{School Development by Type}

In general the number of educational institutions in Nganjuk experience the up and down from the year 2001-2016, this institution consists of preschool education (TK), elementary school (SD), Junior High School (SMP), Senior High School (SMA), and Higher Education (PT).

Ranging from preschool education institutions every year experienced an increase from the year 1995/1996, amounting to 479 institutions to 2013, amounting to 585 agencies. Furthermore, the number of primary school institutions has decreased every year. Starting from 756 down to 669 institutions elementary institutions. Then junior high and high instability in a number of institutions each year and the last one is the number of Higher Education Institutions, which increased in the period of five years, until 2013 the number of Higher Education institutions in Nganjuk amounted to 7 College.

\section{Number of Visitors Regional Public Library}

Libraries can be interpreted simply as literacy centers that support the civilization of a society either in the region or regions. Establishment of the library in Nganjuk as a sign that the Government Nganjuk concerned about the progress of society and civilization. The development of knowledge and science is dependent on how many literacy owned by a person or government.

Literacy is very important in dealing with the development of more advanced age. By cultivate reading and discussing literacy center, of making the community more berkembangan in terms of thought, skill and attitude. Talking about the literacy center (library) is certainly related to the subject or visitors to the library itself, because without visitors library functions will not run optimally. The quantity of visitors into the main focus in the development of the public library in Nganjuk.

In 2013, the number of library visitors from January to December experienced ups and downs. But the rise and fall of the number of visitors is only a little difference. Visitors library visitors disaggregated by gender is male and female visitors. Overall the number of visitors to public libraries mostly occurred in March as many as 2,528 visitors, while the total number of visitors fewest occurred in August as many as 2106 visitors. Then the number of visitors to the male and female visitors at most come in June. The number of male visitors as many as 1256 visitors and the number of female visitors as many as 1,272 visitors. Furthermore, the number of visitors at least for the male visitors occur in August as many as 970 visitors,

Comparison of the number of visitors of men and women in the Public Library of Nganjuk more visitors than gender Woman. Starting from January to December 2013, meaning that people Nganjuk that readers most of the female sex.

\section{Number of Visitors Cars Book Mobile}

In addition to public libraries, government Nganjuk also provide an alternative for people to stay updated in terms of science and certainly related to literacy. One is a mobile library vehicle, with the more advanced a technology and information create an alternative so that people can still enjoy the knowledge without having to come to the public library, because sometimes people want to come and read books in the public library but is hampered by distance and transportation.

The alternative provided by the Government Nganjuk district, was also utilized by the community. As evidenced by the large number of visitors mobile library. Although not as many visitors at the public library, but the difference in the number of visitors of the mobile library is not much different from the public library visitors.

Facility utilization literacy especially public libraries and the mobile library has been evenly distributed between men and women. Both had the opportunity to develop literacy to explore science as much as possible with government facilities by making use of public libraries and the mobile library well.

\subsection{Gender Profiles in Health}

\section{Public Health Service}

One of the government programs in the welfare field of health for the entire community is to improve health care supported by health facilities were adequate at each district. Several health facilities in Nganjuk such as: hospitals, health centers, health center, clinic, maternity hospitals, and clinics. Each sub-district has provided health facilities, such as a minimum there is 1 health centers and several health centers. There are an increasing number of health facilities from the previous year, although there is also one health facility 
that maternity hospitals are declining from the previous year. Health facilities available will run optimally if accompanied by an adequate number of health workers, in terms of both quantity and quality.

In addition to health facilities and health workers, Also important thing to note is the expansion of health care access, particularly to the poor and women at all levels of society. Such access is highly related to gender issues. Therefore, the government also provides health care system in the form of policies, namely the Regional Health Insurance system (Jamkesda) are now integrated in BPJS.

BPJS services in Nganjuk has been uneven in terms of gender, the participants spread of male and female. Participants men and women alike take advantage of the system that makes it easier to access health care services. Government Nganjuk cooperate with various parties in building public health. The health care system is considered to be very beneficial for the community.

Some things in the field of health is also important to highlight the government Nganjuk is health for pregnant women and infants. Because it affects the Maternal Mortality Rate (MMR) and Infant Mortality Rate (IMR).

\section{Maternal Mortality Rate (MMR)}

MMR is the number of maternal deaths due to pregnancy, delivery and post-childbirth per 100,000 live births in a particular period. In 2012, MMR in Nganjuk ranks 4th highest in East Java that is equal to 151.92 per 100,000 live births. Meanwhile, the maternal mortality rate in 2014 dropped to as many as 17 people. Then, for 2015 until last September had been 10 cases of maternal mortality in Nganjuk.

From the information ranked in Nganjuk maternal mortality has decreased significantly. Efforts are being made to produce results that boast, which previously was ranked 4 in East Java (2012) to rank 16 (2014). Nevertheless, the government continues to try to improve health services related to the safety of pregnant women. This figure should reach zero. One way to prevent the high maternal mortality rate, it is necessary to determine the cause of MMR. MMR can be influenced by several factors. Factors that influence the MMR is as follows.
Table1. Factors Influencing Maternal Mortality Rate (MMR)

\begin{tabular}{lc}
\hline \multicolumn{1}{c}{ Factor Affecting } & Percentage \\
\hline Infection & $4 \%$ \\
\hline Hard Preeclampsia & $24 \%$ \\
\hline Cordis Decompensasi & $12 \%$ \\
\hline Pulmonary TB & $4 \%$ \\
\hline Hemorogich Post Partum (HPP) & $4 \%$ \\
\hline hyperemesis & $4 \%$ \\
\hline Lung Ca & $4 \%$ \\
\hline Brain tumor & $4 \%$ \\
\hline Stroke Embolism palsey & $4 \%$ \\
\hline Pregnancy Etropik Disturbed & $4 \%$ \\
\hline Ait Embol Membranes & $4 \%$ \\
\hline Chronic Renal Failure & $4 \%$ \\
\hline Heart & $4 \%$ \\
\hline Abortion & $4 \%$ \\
\hline
\end{tabular}

From Table 1 it can be seen that the factors that have the most impact on maternal mortality adalaha severe preeclampsia / preeclampsia, which reached $24 \%$ and is the second largest factor Decompensasi Cordis, which reached $12 \%$. Another factor has the same percentage, ie $4 \%$. In addition to these factors, MMR also be affected by chronic energy deficiency.

Chronic energy deficiency in pregnant women is a nutritional deficiency in pregnant women long-lasting (months or years). Based on the research findings note that many pregnant women who experience chronic lack of energy.

\section{Infant Mortality Rate (IMR)}

IMR is the number of infant deaths under one year per 1,000 live births in a given year. Infant Mortality also has some of the factors that influence it, one of whom is a toddler with severe malnutrition. There has been no significant drop pattern. Apart from the factor of children malnutrition, infant mortality rate is also affected by factors that are summarized in the following table.

Table 2. Factors Influencing Infant Mortality Rate (IMR)

\begin{tabular}{lc}
\hline \multicolumn{1}{c}{ Factor Affecting } & Percentage \\
\hline Meningitis & $0.69 \%$ \\
\hline Dengue Hemorrhagic Fever & $0.34 \%$ \\
\hline Pnemounia & $3.79 \%$ \\
\hline Diarrhea & $2.76 \%$ \\
\hline Abnormalities Konginental & $9.31 \%$ \\
\hline Aspiration & $1.38 \%$ \\
\hline Low Birth Weight Babies & $41.72 \%$ \\
\hline Asfeksia & $27.59 \%$ \\
\hline Birth trauma & $1.03 \%$ \\
\hline Others & $11.38 \%$ \\
\hline
\end{tabular}


From table 2 it can be seen that the highest factor in influencing the infant mortality rate in Nganjuk is Low Birth Weight Infants, which reached $41.72 \%$ of the total. The second highest factor is Asfeksia, which reached $27.59 \%$, and other factors beyond the factors mentioned factor the third highest, reaching $11.38 \%$. Similarly, the neonatal mortality rate, the highest influencing factor is Low Birth Weight Infants at $51 \%$, followed by asfeksia by $33 \%$. It is as shown in Table 3 below.

Table 3. Factors Influencing Neonatal Mortality Rate

\begin{tabular}{lc}
\hline \multicolumn{1}{c}{ Factor Affecting } & Percentage \\
\hline Low Birth Weight Infants & $51 \%$ \\
\hline Asfeksia & $33 \%$ \\
\hline abnormalities Konginental & $8 \%$ \\
\hline Others & $8 \%$ \\
\hline
\end{tabular}

These factors affect the rate of infant mortality in Nganjuk. The government together with the health department and local movers PKK has sought to suppress the infant mortality rate. Infant Mortality Rate in Nganjuk in 2012 ranks first with a rate of 17.62 per 1,000 live births. Whereas, including Neonatal Infant Mortality Rate in 2014 as many as 172 out of 15634 live births. When compared with the previous year, which was in 2010-2013 cases of maternal and infant mortality in Nganjuk tends to fall, this reduction effort would be appreciated and supported, the important thing is not to become complacent because all regardless of maternal and infant mortality rates are not just numbers but concerning human lives are entitled to a life.

A public health problem is not just the responsibility of the government alone, but also of the community as well as people in their environment. As is the case with later maternal health affects the health of the baby as well, it is the responsibility of pregnant women are concerned, government, family and community environment especially her husband. Maternal deaths is largely influenced by the factors previously described, but it is inevitable that there are other factors that also affect important enough.Suppose, empowerment women who are not so good, educational background, socioeconomic family, community and political environment, the policy also has an effect.

In addition, kaum men are also required to seek to be active in all matters the field is more responsible reproduction. Due to lack of male attention towards the mother pregnancy and childbirth also apply to this case. Therefore, the view that considers Pregnancy is a natural event that needs to be changed sociocultural women could interest from the public. Indispensable effort improvement of maternal care services by the government, private sector, and community, especially husbands and thus creating gender equality in preventing MMR and IMR.

\subsection{Gender Profiles in Economics and Labor}

\section{Labor Force Participation}

Labor force participation rates of women are much lower than for men. Gender inequalities in the economic sector is still a big problem for the empowerment of rural communities. Women tend to be identified with 'pupur, kasur, lan dapur' (make up, bedroom, kitchen. This means that the task of fulfilling the needs of the household economy is not the responsibility of women, they are more emphasis on beauty, service to the husband, and cook for the household. It is appropriate fulfillment of the right to decent work for women is important to highlight. This participation is determined by the presence or absence of jobs that are accessible to women, their ability to maintain and develop the business, and protection in the workplace. Various acts of sexual harassment that every day more rampant needs to be eradicated completely.

Residents who enter the labor force is the work of the working age population (employed), unemployed and looking for work (unemployed). Which fall into the category instead of the labor force (not in the labor force) is the working age population who are in school, taking care of the household, and carry out other activities (pension or disability).

By looking at poverty in Nganjuk then from here then it can be seen in labor force participation in society. Comparison between the number of labor force with the amount of labor that became known as the Labor Force Participation Rate (LFPR). The factors that affect the value of LFPR among others, is the number of the school population, the number of people who take care of the household, the level of wages, education level and more.

\section{Workers By Main Employment Status}


Employment status is the status of a person to do the job in a single business unit / activity. Job status indicators basically looked at four different categories of the working population group that paid labor force (workers), workers who seek their own, free workers and family workers. Trying themselves are generally divided into two, namely those who seek (businessman/businesswoman) with the help of paid workers and those who try without the assistance paid workers, while workers' families also known as unpaid workers.

\section{Workers by Sector Formal/Informal}

Works included in the formal sector are those who work with the business status as laborers or employees with a fixed number of working hours, there is a clear wage and salary, and no attachment and clear rules in the works. Included in the informal sector are those who work with status than as a laborer or employee with no fixed working hours and no particular attachment to enter into a business (no bond and easily change jobs). That work includes housework, subsistence production and the production of goods on the market that are not paid. This definition should not be confused with "unpaid family workers."

Neoclassical approach vehemently rejected the term 'unpaid' because according to the neoclassical assumption of labor supply decisions made voluntarily and rationally with the hope of reward, whether in the form of goods or cash. However, the term is useful analytical relating to the performance of domestic workers for its products, maintenance labor is a boon for the economy as a whole. Macroeconomics itself lucky of public procurement; as a 'free riders' who are paid by women who constitute the main labor force in the unpaid sector (see externality).

This is the contradiction among the public, especially on jobs identified with gender. This is because they attach the assumption that women are subordinate to that they do the jobs that are considered unimportant that need not be paid where women are still a lot of work in the domestic sector chores in the household family. The low percentage of women workers in both the formal and informal sectors because most women belong to the unpaid workers or workers in the domestic sector.

\section{Job Seekers and Job Vacancy}

Welfare in economics certainly does away with the level of employment. Whether it formally or informally in the company. Meeting the needs of formal sector employment occurs because of the jobs that have not been fulfilled. Thus, in the country's economic program to promote these two things can not be separated, ie job seekers and job openings. Most of the cases in this country is the explosion in the number of job seekers but job that opened very sendikit causing unemployment.

For gender cases have been found, usually a lot of jobs but only for men only, while jobs for women was minimal due to the long-held assumption that the required work are men only, while women only served as a housewife. It is also the duty of the government to generalize between men and women because both have the same right to get a job.

Provision of jobs in Nganjuk been evenly between men and women. Even the number of vacancies registered and has fulfilled many of the women with a ratio that is large enough.

\section{Employment and Education Level}

Education is oneliaison to achieve success in the world of work, in Nganjuk have recorded job seekers who have been placed according to their education levels. The greatest number of job seekers who have been placed in 2013 were job seekers with education past elementary school, junior high school, and senior high school/equivalent. Comparison between the number of job seekers men and women who have placed job seekers showed more women than male job seekers.

\section{Unemployment}

Efforts structural changes to improve productivity and create employment opportunities in an effort to improve the welfare population often can reach all elements of the population itself. Opportunities and opportunities of each population is different from one another. Similarly, in the development process, the problem of poverty and unemployment is on the negative effects of the implementation of the development in the form of social inequality.

The unemployment problem is generally more prevalent in urban areas as the effects of industrialization. Unemployment occurs due to imperfect labor market, or not mampunyai labor market to absorb the existing workforce. That places a number of workers who are powerless in economic activities. This is an indirect result of the supply of labor in the 
labor market exceeds demand labor to fill employment opportunities created.

\section{Poverty}

Poverty has always been a major problem in Indonesia as well as in Nganjuk. The government has sought to create programs to reduce poverty, but the results are still not up because there are obstacles in the poverty reduction program as one of them is culture.

The problem of poverty is a problem that even if human civilization is believed to have the same age but cannot be analyzed comprehensively and deeply until now. This is because there is no single concept that can be universally accepted, and no single method of measurement is widely accepted. The problem faced by the poor segments of 'gurem' the farmers can be rooted out of the assets that were simply too small, and the nature of problems in the form of irrigation infrastructure does not support. Root causes small traders, small craftsmen, scavengers, unemployment, seasonal workers, and so on can be different. If the problems that make them difficult to get out of the cycle of poverty can be identified with either the proper program will be formulated. The poverty profile should be present on the root problems as it is, is about more problems rooted in his factor, infrastructure or structural problem, the problem of skills, and so on. The information provided in SUSENAS cannot disclose the problem completely because it is information about the characteristics of poor households.

In an effort to reduce poverty it has done cross-sectoral coordination in Nganjuk, including the implementation of aid utilization garden plants for agriculture and animal husbandry, capital assistance to small businesses through government and nongovernment, including support equipment home industry for women so as to improve the family economy, guidance and assistance to UMKM in Nganjuk has begun to lead to women entrepreneurs because it is seen that women are more diligent and given to the housewife in an effort to supplement the family income.

\subsection{Gender Profiles in Social and Culture: The Case of Early Marriage in Nganjuk}

The phenomenon of early marriage is not new in Indonesia. Even in ancient times marriage age 'mature' would lead to the assumption bad in the eyes of society. Women who do not get married it will receive a response skewed or commonly called a spinster, but over the times, people's views on the contrary. Globalization that go fast changing the way people view. Women who marry at a young age is considered as a taboo. Even further, it was thought to destroy the future of women, suppress creativity and prevent a woman to gain knowledge and insight wider. Therefore the government issued a regulation in setting the minimum age of marriage, which would have been through the process and the various considerations. This meant that both sides really ready and mature in terms of physical, psychological and mental. Actually, parents want their children to school before, but sometimes they feel embarrassed by a neighbor who asked when his son would get married.

The impact of marriage at an early age that emotions are still unstable, turbulent young blood, and ways of thinking are not yet mature. Viewed from many aspects of early marriage does have many negative effects. Therefore, the government only provides wedding tolerance over the age of 19 years for men and 16 for women.

In some order of a society, there are still some understanding of matchmaking. Where his daughter had been betrothed since childhood his parents. The girl child will soon be married shortly after he had a menstrual period.

From some of the causes of early marriage, early marriage that happened not only because of the factor of children, the elderly and cultural factors also took part in this, and most of the victims are girls. This culture needs to be erased in order to achieve equality of rights between boys and girls as well as the realization of a good marriage according to the law and religion.

Nganjuk is one of the locations where they are found early marriage phenomenon. The phenomenon of early marriage in Nganjuk quite high. It is known from residents who live in a rural area with the intensity of education is still minimal. Early marriage is the case in the age range 15-18 years. This is very worrying due to the young age feared prone to problems that will arise in the future. However, early marriage at the level of the periphery or border communities have become a culture that is common in people's lives Nganjuk especially in suburban areas. Early marriage is not taboo but has become a tradition at the level of people's lives. This is because the parents also support early marriage. 
The phenomenon of early marriage in Nganjuk occur due to several factors, including low levels of education for the people who live in suburban areas, access to education, especially education upper secondary level is still relatively far away, economics, and culture of the society has made marriage as a matter of course. The phenomenon of early marriage occurs is also not the result of mating by parental status of children of their own faith but to get married. So what happens parents are always the wishes of children with reason in order to provide happiness for children. Early marriage cases that happen to occur in the age range pass elementary education and junior high school level. The phenomenon of early marriage is not limited to just one country, but also between villages.

Family life did early marriage is economically still financed by parents. This happens due to the husband's job is to help parents farmed. So that life is still dependent on their parents. This is actually a common phenomenon. Given the mental age of the child who did early marriage is still not stable, fulfilling family responsibilities in the economy can not be fulfilled.

The practice of early marriage in Nganjuk that occur at the level of society is quite alarming because women age yet legally valid marriage and legislation. To overcome this, the formerly married religiously do while waiting for ages that have been determined by law. From where problems will occur, because in this waiting period would also cause problems in the family. If it happens then it is clear that the women will be victims, whether victims of psychological and physical violence as well as prone to divorce. High parental intervention for the life of early marriage is still a dependent parent, so it will give rise to potential conflict in family life.

\section{DISCUSSION}

School development can be seen through the number of private schools and public institutions that are in Nganjuk. Number of school institution closely connected with the implementation of the process of learning and teaching in formal education. More and more school institutions, more and more are also learners who are able to be facilitated in the implementation of educational programs. Profile picture of education in Nganjuk there are still many gaps between women and men. This condition is caused by a factor of education costs are still relatively high. With the relatively high cost of education that resulted there are some people who are not able to enjoy the basic rights of every citizen of the right to education. In addition to the cost factor. At the same time, female pupils show that they do not apply, on an equivalent form to his male partners, the above mentioned learnings in the rest of subjects (García-Gil \& Andreu, 2017).

Another reason that also greatly affect the low level of female education dibadingkan with men is their view of prioritizing and putting men to get an education. Determine the skills required by students under study to quickly perceive similarities and differences of stimulating patterns partially ordered and contrast and possible differences based on gender or cultural background of the students (Caballero, et al., 2017). Norm in rural communities, men are considered to have a greater responsibility to provide for their families. While women are expected skilled in the field of household only. Gender inequalities are still present, they are reproduced in education and are visible in different roles, functions, duties and expectations for men and women (Steffena \& Krob, 2015). This must be addressed so that boys and girls receive equal rights in education. When necessary, efforts must be made to provide students with the necessary skills so that they can make the most of the educational potential these tools offer (GarcíaGil \& Andreu, 2017).

Health is a prime state of body, soul, and a social person so the effect on the level of work productivity. Health is defined as a state of complete physical, mental and social wellbeing and not merely the absence of disease or infirmity (Jeyagurunathan, et al., 2017). Health is one of the indicators in achieving the country's development objectives as set out in the MDG's. At the MDG's own field of health has a very important position. Health is also used as a determinant of well-being in a society. Therefore, the government made efforts to create a healthy society.

The government's efforts in achieving the welfare of the people in the health sector among others by providing health services such as health facilities and health sector workforce. UU number 17 in 2007 on RPJPN which states that the development challenges facing the health sector is to reduce inequalities among public health status and access to health care between regions, socioeconomic level, and gender. Thus, the 
provision of health services for the community is expected to reach all levels of society as a whole regardless of their socioeconomic level and gender. Health care centers generally serve for both men and women, but there are also clinics that cater specifically to women and children. Gender-specific integrated health services have long existed in the arena of women's health care, but men's health centers (MHCs) have only recently emerged as a novel practice model (Choy, et al., 2015). In this regard it is necessary services that help improve the health awareness issues for men. As the discipline of men's health continues to develop, health policy and governmental initiatives promoting men's health could aid in increasing public awareness of men's health issues (Choy, et al., 2015). All the people, both men and women and rich and poor have equal opportunities in access to health services. Historically, intersectionality has been an underutilized framework in sociological research on racial/ethnic and gender inequalities in health (Richardson \& Brown, 2016).

Economic and employment are two things that can not be separated. Both affect each other, and both are also an important indicator of a person can be said to prosper apart from the aspects of health and education. Employment opportunities for Indonesian citizens is a right guaranteed by the state, as stated in the UUD 1945, article 27, section 2, which states that "Every citizen is entitled to work and a decent living". To that end, the government has a great responsibility in providing jobs for its citizens.

Economic and employment are also included in the country's development objectives. Indicators of economic and employment can provide an overview of the economic absorptive capacity to population growth and labor productivity. If the economy can not absorb the growth in the labor force increases in unemployment can not be avoided so that in the end, the number of unemployment will lead to a lot of the social problems. In addition, information and conditions of employment of a region is becoming increasingly important since one of the goals of development is to create jobs in sufficient quantity and quality and ultimately aims to improve the lives and welfare of the community.

The strategic measures are necessary to ensure the right to work is to improve women's access to employment opportunities. Women must be empowered to be able to develop the business through concerted measures to create jobs. Labor economists have used a variety of variables to explain women's decisions to participate in the labor force (Ramírez, et al., 2015). At the village level increase laborintensive investment that has been done should also be prioritized for women, not just men are being targeted. In addition, women and married people make up a large fraction of the population and of labor market participants, total hours worked, and total earnings (Borella, et al., 2017). In addition, business development and off-farm employment; increased access to information, technology and markets; develop institutions capable of fighting for poor women's access to employment opportunities needs to be fought by good. Based on this idea, there was the need to further the knowledge on the gender of the individual who creates a social enterprise, as this type of organization is more consistent with the roles and characteristics attributed to women (Nicolás \& Rubio, 2016).

Analysis of the labor force in relation to the condition of the economy is an interesting thing to do because of the level and pattern of labor force participation tends to depend on the availability of employment opportunities and differences in the demands of earning between population groups. Labor force participation rate shows the magnitude of the ratio between the number of labor force to the working age population.

Unemployment diketagorikan into three: 1) half the unemployed are unemployed who are between full working level and at all unemployed, underemployed composed of the visible and the invisible underemployment; 2) unemployment is not seen is that they are incorporated into the activities of work, but in fact they are unemployed when seen in terms of productivity; 3) frictional unemployment is unemployment that occurs due to the movement of persons from one job to another job, the result should have a time limit and status as unemployed before getting another job.

Indicators used to measure open unemployment is the unemployment rate. The open unemployment rate is generally defined conventionally as a proportion of the workforce that is not working and looking for work. These sizes can be used to indicate how big the job offers that can not be absorbed in the labor market in a country or region.

Marriage is a binding promise of marriage ceremony that celebrated or carried out by two people with the intent of matrimony legally 
formalize religion, state law and customary law. The wedding ceremony has many varieties and variations between nations, tribes and the other one on one race, religion, culture, and social class. The use of custom or specific rules are sometimes associated with certain religious rules or laws anyway.

Early marriage means a grand instituisi to bind two people of the opposite sex who was a teenager in the family ties. There are several factors causing early marriage, the personal factors and family factors. From personal factors teenager is because they want to avoid $\sin$ (free sex), and some are due to 'married by accident'. While the family factor is because of coercion from parents. It has become customary here that women aged $14-15$ is only fitting to get married.Maturity mother both physically and mentally is crucial, because it will affect the future development of the child later. It is therefore very important to consider the age of children getting married. Although the marriage age limit specified in article 7 section 1 of UU number 1 in 1974, "that marriage is only permitted if the man has reached the age of 19 years and the woman has reached the age of 16 years." But in practice there are still many encountered a wedding on youth or minors.

Many things behind someone doing early marriage. such as the lack of education, because the economic crush of parents, as well as the tradition that has evolved in the environment community. These conditions will raise many questions from the public if it happened because of poor parents to supervise the child or there are other factors, but parents can not always be blamed if environmental conditions are established that early marriage is already common practice.

Early marriage causes various problems, such as in terms of maintaining their egos. They are still in a fragile and unstable age, helped trigger domestic conflicts that lead to divorce. Nevertheless, it is undeniable that not all early marriage has negative impact for a family, because many of those who have been married at a young age to maintain the integrity of the family in accordance with the purpose of marriage itself.

Marriage is important, because with one's wedding will acquire the balance of life, both biologically, psychologically and socially. With a wedding, then the biological needs can be met. He can distribute the biological needs with his or her spouse. While it is mental or spiritual people who are married in the mature age more in control of his emotions in the face of various problems in the family. A large number of literature on education of women clearly suggest that educating a woman is equal yo educating a family and that woman are worth training than their counterpart, men, in many respects (Yumusak, et al., 2013).

Emotional maturity is a very important aspect to maintain the continuity of marriage. Domestic success is largely determined by the emotional maturity, both husband and wife. With the holding of marriage, their social status in the society is recognized as spouses and legally. The age limit in the wedding ceremony is also important. This is because marriage requires psychological maturity. Marriage is too young age can result in increased cases of divorce due to lack of awareness to take responsibility in domestic life.

Successful marriage often characterized by the readiness of the responsibility is shared. Once you decide to get married, they are ready to bear all expenses incurred as a result of marriage, both concerning the provision of livelihood, education of children, as well as those related to the protection, relationships, and have offspring. Maturity mother also affects the development of children, because mothers who have grown psychologically would be more restrained emotion and action, when compared with younger mothers. In addition to affecting the physical aspect, maternal age also affects the psychology of the child. A mother whose teenage actually not ready to be a mother, both in terms of parenting skills and educate their children. The properties of rejuvenation as emotionally unstable. The study of the use of Information and Communication Technology (hereinafter ICT) in the different education levels and branches of knowledge is a well-established line research that has generated an extensive and interesting body of scientific literature (Asian \& Zhu, 2015; George \& Onniyi, 2016; Uluyol \& Sahin, 2016).

\section{CONCLUSIONS AND SUGGESTIONS}

\subsection{Conclusions}

Gender profile education indicate that data segregation between men and women go well. Utilization of services by the government education facility can be said evenly between men and women. However, there is some 
inequality in the division of roles between boys and girls in the process of learning at home and at school.

Gender profile field indicates that the data segregation between men and women is not maximized. Health care facilities provided by the government has been distributed to the general public evenly through Jamkesda service system which then transferred the BPJS system. Health cases is still the talk of the MMR and IMR. Factors that affect both physical health is concerned, but there are other factors that are not less important is the level of empowerment of women and the rate of maternal care.

Gender profile economics and employment indicate that data segregation between men and women is not maximized. Only a few data have been disaggregated by gender, ie the data of workers by main employment status, job seekers and job openings. There are no gender segregation in the labor participation rate of data and unemployment data.

Socio-cultural gender profile field that focuses on early marriage shows that culture is a determining factor of gender inequality. Early marriage is determined more by cultural factors as compared to other factors such as education or economics.

\subsection{Suggestions}

Socialization of gender mainstreaming in all SKPD for recharging of the importance of sorting data for women and men in all documents. The data referred to in the fields of education, health, employment and socioculturally appropriate, including in this case is the exposure data in the Figures Nganjuk books that have been disaggregated kinds of men and women on the data allows.

Socialization that involves cross-sectoral to overcome early marriages concerning aspects of health, education and employment. Maximizing the role of women before and after marriage especially those that can be implemented through cottage industries.

Creating and implementing regulations before marriage must demonstrate junior high school diploma. The goal is that 'Program Wajib Belajar' 9 years accomplished and successful as well as early marriage can be inhibited because the bride and groom to be graduated from high school first.

\section{ACKNOWLEDGMENT}

The researcher would like thank to: (1) Badan Pemberdayaan Perempuan dan Keluarga Berencana (BPKB) of Nganjuk who facilitate the independent research, (2) Head of District Sawahan, (3) Head of Nonformal Education Program, Postgraduate Program, Universitas Negeri Malang, (4) Team of Indonesia LED Consultant, (4) All people who helped the researcher in the process of research.

\section{REFERENCES}

[1] Asian, A. \& Zhu, C. (2015). Pre-Service Teachers' Perceptions of ICT Integration in Teacher Education in Turkey. Turkish Online Journal of Educational Technology, 14(3), 97-110. doi: 10.13189/ujer.2016.040119

[2] Bogdan, R. C. \& Biklen, S. K. (2007). Qualitative Research for Education: An Introduction to Theory and Methods. Boston: Allyn and Bacon, Inc.

[3] Borella, M., Nardi, M.D. \&Yang, F. (2017). The Aggregate Implications of Gender and Marriage. The Journal of the Economics of Ageing. xxx (2017): 1-21. (http://www.sciencedirect.com/science/arti cle/pii/S2212828X16300494)

[4] Bungin, B. (2011). Penelitian Kualitatif. Jakarta: Prenada Media Group

[5] Caballero, A.O., Casares, J.A.V. \& Caballero, M.O. (2017). Visual Perception in Art Education. Gender and Intercultural Study. Procedia - Social and Behavioral Sciences, 237, 588-593. (http://www.sciencedirect.com/science/arti cle/pii/S1877042817301118)

[6] Choy, J., Kashanian, J.A., Sharma, V., Masson, P. \& Brannigan, R.E. (2015). The Men's Health Center: Disparities in Gender Specific Health Services among The Top 50 "Best Hospitals" in America. Asian Journal of Urology. 2, 3, pp. 170-174. (http://www.sciencedirect.com/science/arti cle/pii/S2214388215000764)

[7] García-Gil, D. \& Andreu, R.C. (2017). Gender Differences in Music Content Learning using a Virtual Platform in Secondary Education. Procedia - Social and Behavioral Sciences, 237, 57-63. (http://www.sciencedirect.com/science/arti cle/pii/S1877042817300174)

[8] Georges, F. \& Ogunniyi, M. (2016). Teachers' Percepctions on the Use of ICT in a CAL Environmnet to Enhance the Conception of Science Concepts. Universal 
Journal of Educational Research, 4, 1, pp. 151-156.

[9] Jeyagurunathan, A., Vaingankar, J.A., Abdin, E., Sambasivam, R., Seow, E., Pang, S., Picco, L., Chong, S.A. \& Subramaniam, M. (2017). Gender Differences In Positive Mental Health among Individuals with Schizophrenia. Comprehensive Psychiatry. 74, 88-95. (http://www.sciencedirect.com/science/arti cle/pii/S0010440X16303716)

[10] Jung, T. \& Ejermo, O. (2014). Demographic Patterns and Trends In Patenting: Gender, Age, and Education of Inventors. Technological Forecasting \& Social Change. 86, 110-124. (http://www.sciencedirect.com/science/arti cle/pii/S0040162513001911)

[11] Lincoln, Y.S. \& Guba, E.G. (1985). Naturalistic Inquiry. Beverly Hills: Sage Publication.

[12]Moleong, L. J. (2007). Metodologi Penelitian Kulaitatif. Bandung: PT. Remaja Rosda Karya.

[13]Nicolás, C. \& Rubio, A. (2016). Social Enterprise: Gender Gap and Economic Development. European Journal of Management and Business Economics. 25, 2, pp. 56-62. (http://www.sciencedirect.com/science/arti cle/pii/S2444845116000161)

[14]Ramírez, E. \& Ruben, R. (2015). Gender Systems and Women's Labor Force Participation in the Salmon Industry in Chiloé, Chile. World Development. 73, 96104.

(http://www.sciencedirect.com/science/arti cle/pii/S0305750X14003520).

[15]Richardson, L.J. \& Brown, T.H. (2016). (En)gendering Racial Disparities in Health Trajectories: A Life Course and
Intersectional Analysis. SSM - Population Health.2, 425-435. (http://www.sciencedirect.com/science/arti cle/pii/S2352827316300209)

[16] Steffena, L. \& Krob, D.B. (2015). Discourses of Gender in Brazilian Songs: The Influence of Music in Brazilian Education under a Gender Analysis. Procedia - Social and Behavioral Sciences, 174 , 2123-2129. (http://www.sciencedirect.com/science/arti cle/pii/S1877042815013191)

[17] Turturean, C.I., Chirila, C. \& Chirila, V. (2013). Gender Discrimination on the Romanian Labor Market - Myth or Reality? Procedia - Social and Behavioral Sciences. 92, 960-967. (http://www.sciencedirect.com/science/arti cle/pii/S1877042813029157)

[18]Uluyol, C. \& Sahin, S. (2016). Elementary School Teachers' ICT Use in the Classroom and Their Motivators for Using ICT. British Journal of Educational Technology, 27, 1, pp. 66-75.

[19]Undang-Undang Republik Indonesia Nomor 1 Tahun 1974 tentang Perkawinan. 2004. Yogyakarta: Lintang Pustaka.

[20] Undang-Undang Republik Indonesia Nomor 17 Tahun 2007 tentang Rencana Pembangunan Jangka Panjang Nasional Tahun 2005-2025. 2009. Jakarta: Kementerian Negara Perencanaan Pembangunan Nasional/Bappenas.

[21] Yumusak, I.G., Bilen, M. \& Ates, H. (2013). The Impacts of Gender Inequality in Education on Economic Growth in Turkey. Procedia - Social and Behavioral Sciences.103, 1093-1103. (http://www.sciencedirect.com/science/arti cle/pii/S1877042813038822). 